\title{
Análise do Programa Spec20
}

\author{
J. P. LEAL* \\ M. J. MATOS**
}

0 Spec20 proporciona uma simulação interactiva de um espectrofotómetro manual típico, o Spectronic $20^{\circledR}$ da Bausch and Lomb. A semelhança entre a simulação e 0 aparelho real permite adquirir rapidamente um enorme à-vontade na execução das experiências. 0 écran apresenta uma cópia fidedigna do aparelho (com efeito tridimensional), bem como todos os botões de controle e 0 mostrador de medida de transmitâncias (fig. 1). 0 programa apresenta ainda a possibilidade de recolher e analizar os dados ou de os representar graficamente.

Todos os ensaios são realizados sobre a reprodução do aparelho no écran do computador manipulando os tubos das amostras e os botões do aparelho através do rato ou do teclado. Em ambos os casos é bastante fácil a operação pois apenas as operações que podem ser usadas em determinada altura se apresentam activas (os botões activos mostram um aspecto tridimensional e os não activos aparecem a cinzento.) Quando da utilização do teclado as operações são acedidas através da primeira letra da acção a realizar inscrita no respectivo botão e que apresenta uma côr diferente do restante texto.

A reprodução do aparelho real é bastante boa observando-se inclusivé a oscilação característica do ponteiro quando 0 aparelho é ligado. Tenta-se também representar a cor aproximada das soluções em análise e inclusivé a reflexão da luz no tubo da amostra.

No inicio do programa é apresentada uma pequena demonstração da manipulação dos tubos das amostras mostrando a limpeza do tubo, 0 alinhamento e inserção no porta-amostras.

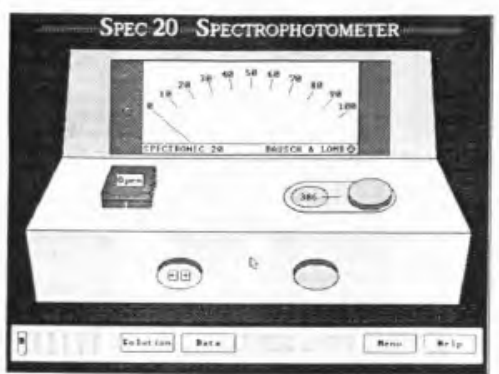

0 objectivo do programa (familiarizar 0 utilizador com a operação de um espectrofotómetro) é conseguido propondo que se determine a concentração de uma solução de concentração desconhecida. Para atingir essa meta, devem ser seguidos os seguintes passos:

- ligar 0 aparelho (rodando 0 botão ON/OFF que também controla 0 acerto da transmitância) e esperar que ele aqueça;

- seleccionar de entre as várias soluções existentes com qual quer trabaIhar e escolher a concentração a usar. A partir desta concentração 0 programa disponibiliza, além da concentração original, mais três tubos com as concentrações $1 / 8,1 / 4$ e $1 / 2$ da original (inicialmente estão disponiveis soluçōes de seis compostos, mas 0 utilizador pode introduzir novos compostos);

- após 0 aquecimento, acertar 0 zero da transmitância quando a luz não passa, fechando o compartimento da amostra e rodando para tal 0 botão de acerto - botão de ON/OFF (esta operação deverá ser feita sem tubo de amostra no respectivo compartimento pois tal como no aparelho real a fonte de luz é automaticamente desligada quando não está inserido nenhum tubo de amostra);

- rodando o botão da selecção do comprimento de onda procurar 0 que corresponde a um máximo de absorção para a substância em estudo (0 programa sugere um comprimento de onda, por exemplo $510 \mathrm{~nm}$ para 0 nitrato de cobalto, mas o utilizador pode escolher outro qualquer);

- colocar o tubo com o "branco" tendo 0 cuidado de 0 limpar e de 0 alinhar antes de 0 introduzir no compartimento de leitura:

- Introduzir o tubo no compartimento e fechar este;

- acertar a escala para $100 \%$ de transmitância;

- após estes acertos deve 0 utilizador medir a transmitância das 4 soluções de concentração conhecida e da solução cuja concentração se pretende determinar não se esquecendo de informar o programa que quer registar os valores (opção Data) pois só assim os

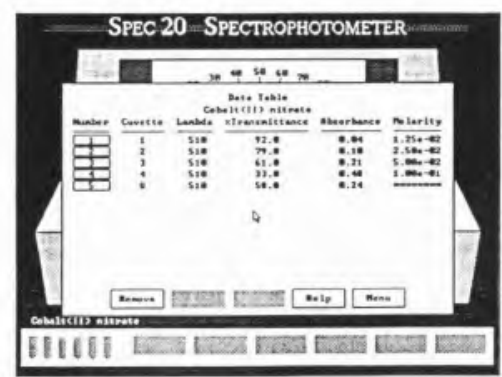

valores são registados para posterior tratamento gráfico.

Os dados recolhidos podem ser consultados (fig. 2) e usados para se obterem vários tipos de gráficos. As opções disponiveis são:

- Tabela de Dados

- Transmitância vs. comprimento de onda

- Absorvância vs. comprimento de onda

- Transmitância vs. concentração

- Absorvância vs. concentração

Neste caso o gráfico que interessa é 0 da absorção em função da concentração, que pela aplicação da lei de Beer nos permite calcular a concentração da solução desconhecida. 0 gráfico obtido (fig. 3) apresenta a recta mais provável para os pontos experimentais medidos, a recta obtida a partir da lei de Beer e 0 valor de concentração aceitável para a solução desconhecida.

Além deste tipo de procedimento 0 programa permite também a análise de uma só solução a vários comprimentos de onda. 0 procedimento é idêntico tendo apenas que se ir variando o comprimento de onda para uma mesma amostra e registar os respectivos valores com a op̧̧ão Data. Um gráfico típico obtido é mostrado na figura 4.

A apreciação global deste programa é bastante favorável pela sua fidelidade ao aparelho real tanto em representação gráfica como em comportamento. No comportamento em relação ao modelo real notámos apenas uma diferença que consiste no alinhamento do tubo. No programa 0 alinhamento faz-se antes de introduzir 0 tubo e na realidade faz-se com o tubo já inserido no porta-amostras e acertando 0 traço deste com 0 


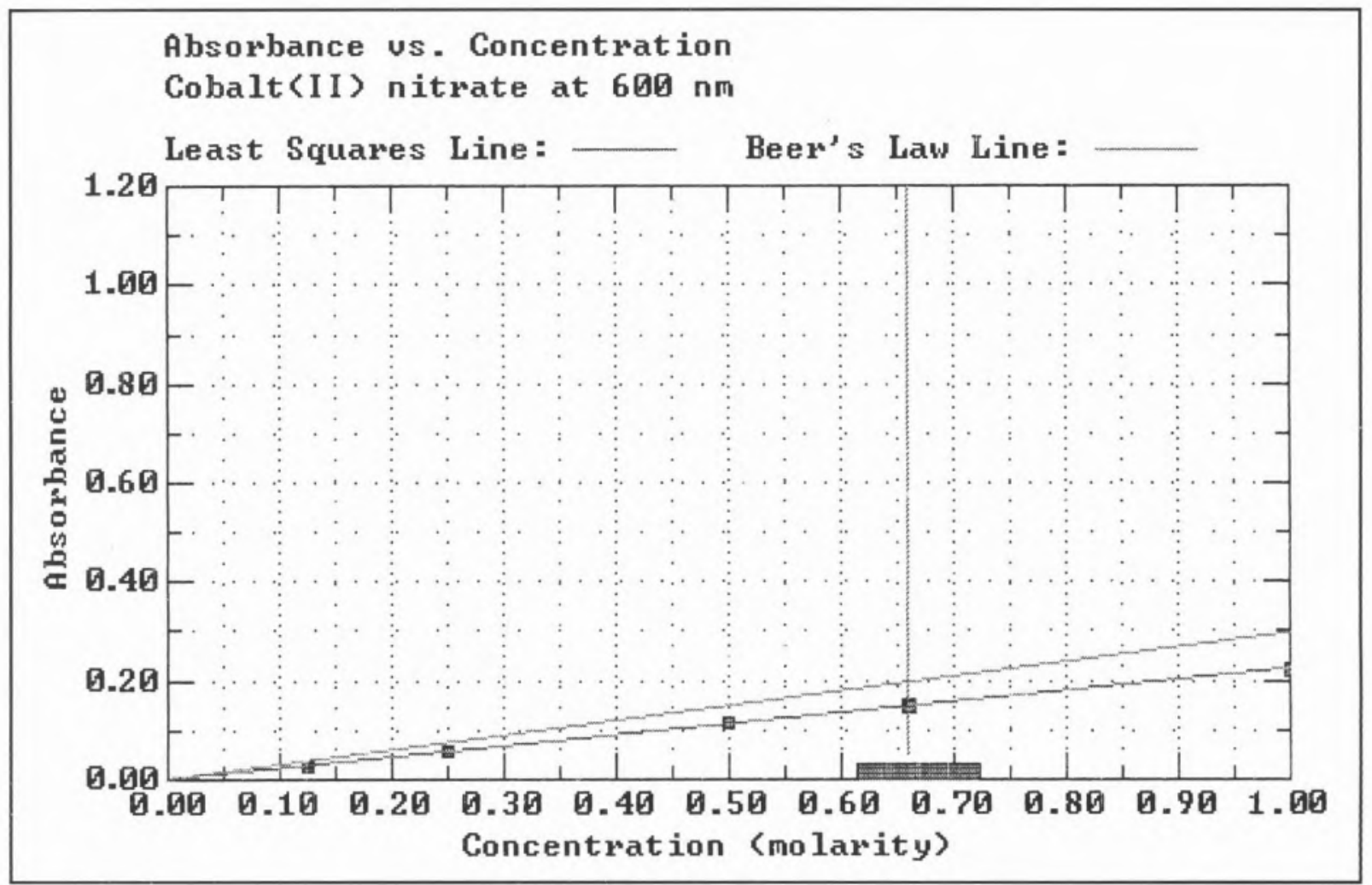

existente no tubo.

Sendo 0 simulador de um aparelho real pode encarar-se sob duas perspectivas: real,

- representar apenas 0 aparelho

— representar o aparelho real com alguma inteligência artificial.

Sob a primeira perspectiva este aparelho é excelente como já dissemos. Sob a segunda pensamos que se poderia ter ido um pouco mais longe em termos de interacção com 0 utilizador que é geralmente um estudante ou técnico de laboratório. Entre outras sugestões pensamos que 0 aparelho deveria informar 0 utilizador quando o tubo não tivesse sido limpo ou alinhado. 0 programa não permite que os valores recolhidos sejam impressos pois mesmo a cópia de écran através da tecla de Print Screen é inibida para qualquer imagem. Os pontos tam-

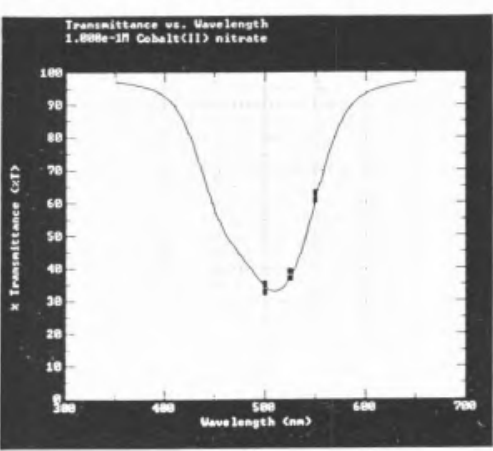

bém não podem ser guardados em ficheiro. As escalas dos gráficos são sempre feitas automaticamente 0 que nem sempre conduz aos melhores resultados, e as linhas que no écran se conseguem distinguir com facilidade umas das outras são impressas de modo dificilmente distinguivel.

Recomendamos o programa para 0 treino de utilização de espectofotómetros quando estes não existam ou para uma utilização prévia do programa antes da utilização do aparelho real (o programa não se estraga...). 0 programa pode ser facilmente usado por estudantes universitários dos primeiros anos ou por técnicos de laboratório experimentados neste tipo de técnicas.

Quaisquer questões poderão ser enviadas para a sede da $S P Q$ ao cuidado dos autores desta análise. 0 programa - Spec20 foi adquirido pela SPQ, e está à disposição dos sócios que o pretendam consultar antes de 0 adquirir.

\section{A nossa classificação:}

$\begin{array}{lc}\text { Cálculo } & - \\ \text { Gráficos } & 5 \\ \text { Interacção com o utilizador } & 4 \\ \text { Impressão } & 4 \\ \text { Manual } & 4\end{array}$

\section{Necessidades de Hardware}

IBM PC ou compativel com placa EGA ou VGA (recomenda-se um écran policromático para aproveitar o belo efeito visual da simulação). Necessita apenas uma drive de baixa densidade (5" 1/4 ou 3 " 1/2), embora um disco rígido facilite as operações em termos de velocidade. Um rato é prático, emboa não seja fundamental. Imprime em impressoras compatíveis com Epson, IBM ou Hewlett-Packard (praticamente todas as impressoras são compativeis com pelo menos um destes modos).

\section{Fornecedor:}

Journal of Chemical Education: Software, Department of Chemistry, University of Wisconsin-Madison, Madison, WI 53706 USA.

Preço:

70 dólares (1993), incluindo também o programa Notebook.

${ }^{*}$ Dep. Química, ICEN-INETI, Sacavém.
${ }^{\star \star}$ Dep. Química, ISEL (Instituto Superior de Engenharia de Lisboa). 